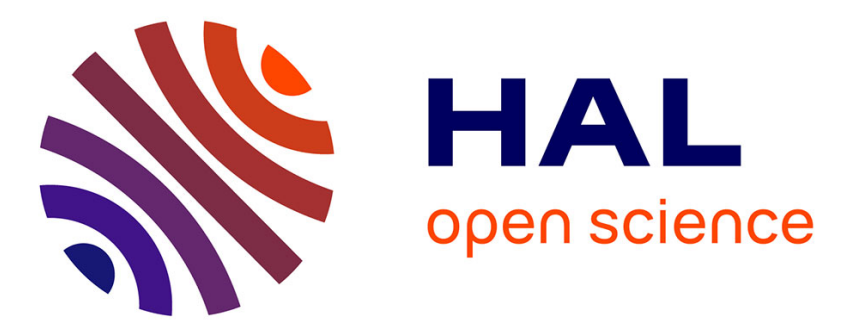

\title{
A methodology to assess habitat fragmentation effects through regional indexes: illustration with forest biodiversity hotspots
}

P. Larrey Lassalle, A. Esnouf, P. Roux, Miguel Lopez-Ferber, R. Rosenbaum, Eléonore Loiseau

\section{To cite this version:}

P. Larrey Lassalle, A. Esnouf, P. Roux, Miguel Lopez-Ferber, R. Rosenbaum, et al.. A methodology to assess habitat fragmentation effects through regional indexes: illustration with forest biodiversity hotspots. Ecological Indicators, 2018, 89, pp.543-551. 10.1016/j.ecolind.2018.01.068 . hal-02022772

\section{HAL Id: hal-02022772 \\ https://hal.science/hal-02022772}

Submitted on 18 Feb 2019

HAL is a multi-disciplinary open access archive for the deposit and dissemination of scientific research documents, whether they are published or not. The documents may come from teaching and research institutions in France or abroad, or from public or private research centers.
L'archive ouverte pluridisciplinaire HAL, est destinée au dépôt et à la diffusion de documents scientifiques de niveau recherche, publiés ou non, émanant des établissements d'enseignement et de recherche français ou étrangers, des laboratoires publics ou privés. 


\section{A methodology to assess habitat fragmentation}

\section{forest biodiversity hotspots}

11 Graphical abstract
Pyrène Larrey-Lassalle * $, \uparrow, \S$, , Antoine Esnouf $\hbar, \S$, Philippe Roux $\dagger, \S$, Miguel Lopez-Ferber \$, , Ralph K. Rosenbaum $\uparrow, \S$, and Eléonore Loiseau $\uparrow, \S$ $\dagger$ Irstea, UMR ITAP, ELSA-PACT_-Industrial Chair for Environmental and Social Sustainability Assessment, 361 rue J.F. Breton, 5095, 34196 Montpellier, France \$ Ecole des mines d'Alès, Centre LGEI, 30319 Alès, France † LBE, INRA, Montpellier SupAgro, 11100 Narbonne, France

12

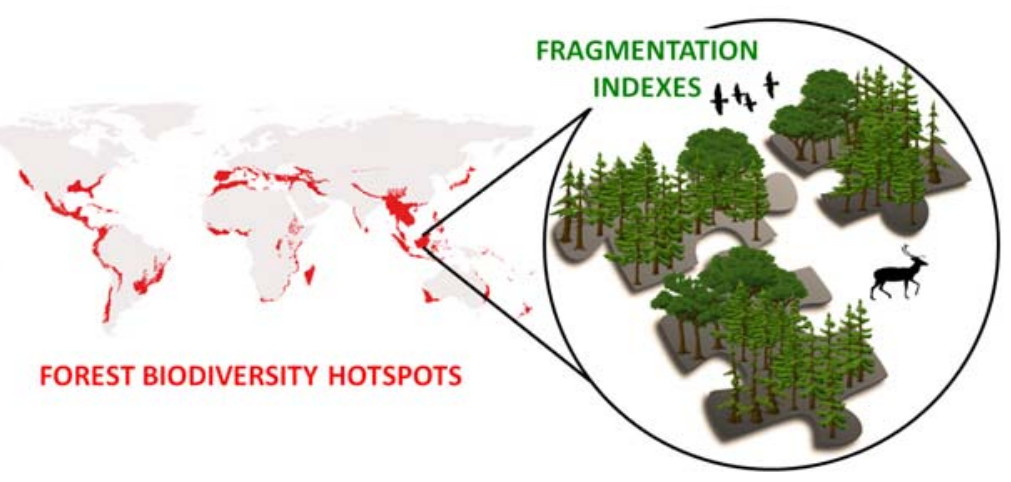




\section{Highlights}

15 A methodology to derive worldwide regionalised fragmentation indexes is developed.

It was applied to all forest ecoregions included in the biodiversity hotspots.

The results highlighted significant intra- and inter-ecoregions differences.

These indexes can be used for land use planning or macro-scale conservation planning.

\section{Abstract}

The fragmentation of natural environments is a critical issue involving major challenges for biodiversity conservation and ecosystem management. Large-scale information on areas sensitive to fragmentation is needed to improve the effectiveness of planning efforts. One promising metric combining the landscape spatial configuration with species characteristics is the metapopulation capacity $\lambda$, which can be used to rank different fragmented landscapes in terms of their capacity to support viable metapopulations. A methodology to globally derive a fragmentation metric based on metapopulation capacity, at appropriate and meaningful spatial scales for fragmentation mechanisms, was developed. To illustrate the applicability and interest of the methodology, worldwide regionalised fragmentation indexes, calculated with a dispersal distance of $1 \mathrm{~km}$ valid for a broad range of species, were provided for all forest ecoregions included in the biodiversity hotspots. Ecoregions were divided by a virtual grid and a statistical analysis of metapopulation capacity values calculated at the grid square scale was performed to obtain a Forest Fragmentation Potential FFP at three levels of spatial aggregation within the ecoregion (highly converted forest, entire forest, and the whole ecoregion). The results highlighted significant intra- and inter-ecoregions differences, showing great potential to extend 
the use of these indexes to land use planning and areas prioritisation for both ecological protection and restoration. The influence of the different parameters used in the proposed approach is discussed as well as the limitations of the main assumptions. One important result is that the derived methodology can be easily adapted to a large number of species, scales, or regions to improve the coverage of fragmentation indexes.

\section{Keywords}

Landscape spatial configuration; Forest loss; Metapopulation capacity; Large-scale indexes; Biological conservation; Global maps

\section{Introduction}

In December 2016, the Conference of Parties for the Convention on Biological Diversity (COP13) gathered together 196 countries in Cancún with the objective of stopping the dramatic decline of terrestrial and marine biodiversity. WWF recently estimated that by 2020 , at the current biodiversity loss rate, the world will have witnessed a two-thirds decline in global wildlife populations in only half a century (WWF, 2016a). And yet, of the twenty Aichi biodiversity targets (Convention on Biological Diversity, 2016), only four are partly reached or in the process of being reached, while for all others the situation still stagnates or even worse, for five of them, deteriorates (e.g. damages to coral reefs, pollution from excess nutrients, or most endangered species protection) (Secretariat of the Convention on Biological Diversity, 2014). Increasing international trade in our globalised economy accounts for a significant share of biodiversity threats (Chaudhary and Kastner, 2016; Lenzen et al., 2012; Moran and Kanemoto, 2017). In particular, consumers in developed countries cause threats to species through their 
Author-produced version of the article published in Ecological Indicators, 2018, N ${ }^{\circ} 89$, p.543-551.

imported supplies from developing countries (Moran and Kanemoto, 2017). Similarly, numerous

Life Cycle Assessment (LCA) studies showed that complex international value chains have environmental impacts, among others on biodiversity, all over the planet (de Baan et al., 2015; Hellweg and Mila i Canals, 2014). Land conversion from primary ecosystems to urban, industrial or agricultural land is a major biodiversity threat that has been studied for some years. The importance of subsequent environmental fragmentation, for which the situation is getting worse with respect to the corresponding Aichi biodiversity target (Convention on Biological Diversity, 2016), has been recognised more recently. However, to date most fragmentation studies have focused on the local scale whereas there are few analyses at regional scales or they are limited to the temperate zone or the tropics (Bregman et al., 2014). Except for a pioneering work that identified global fragmentation hotspots for mammalian carnivores (Crooks et al., 2011), global patterns of habitat fragmentation and connectivity have not yet been examined, even if long-term experiments indicated that fragmentation effects are considerable and clearly consistent across a diverse range of terrestrial systems on five continents (Haddad et al., 2015). A study conducted at the biogeographical scale also showed that incorporating fragmentation metrics into largescale models may contribute for a better understanding of species distributions (Reino et al., 2013). With this in mind, global maps characterising the impacts of habitat fragmentation on species with relevant ecological indicators would be very useful for taking the appropriate decisions and actions for biodiversity conservation (GEO BON, 2015).

Fragmentation is commonly defined as a landscape-level process in which 'a large expanse of habitat is transformed into a number of smaller patches of smaller total area, isolated from each other by a matrix of habitats unlike the original' (Wilcove et al., 1986). Landscape structuration analysis is commonly conducted in parcels ranging in size from around $3 \mathrm{~km}^{2}$ to $300 \mathrm{~km}^{2}$ 
(Fischer and Lindenmayer, 2007), and often set to $100 \mathrm{~km}^{2}$ for different species in various studies (Atauri and de Lucio, 2001; Radford et al., 2005). Fragmentation typically leads to the reduction of landscape connectivity, which is defined as the degree to which the landscape facilitates or hinders organisms movements among habitat patches (Taylor et al., 1993). Management to maintain or restore connectivity is crucial to ensure the survival of many species and preserve biological diversity. Therefore, many authors proposed metrics to measure habitat connectivity at the landscape scale (Kindlmann and Burel, 2008; Ortega, 2010; Wang et al., 2014). Calabrese and Fagan (2004) proposed to distinguish between three main classes of connectivity metrics. First, the structural connectivity can be directly derived from landscape physical attributes (e.g. composition, shape or configuration metrics (Rutledge, 2003)). These types of indicators range from 'simple' landscape structure metrics (e.g. number of fragments) to more complex landscape indices (e.g. effective mesh size (Jaeger, 2000)), and dedicated software such as Fragstats (McGarigal, 1994) or, more recently, Conefor (Saura and Torne, 2009) have been developed to easily compute them on different spatial levels. Data has also been collected to quantify structural fragmentation globally (Haddad et al., 2015; Riitters et al., 2000). Second, the potential connectivity combines the landscape physical attributes, obtained from the structural connectivity analysis, with information on the focal species dispersal ability. Finally, the actual connectivity is based on observed or quantified (e.g. through species distribution models) movement pathways in the landscape. Structural connectivity is the easiest to collect, but it has a limited interest since it does not consider the species characteristics. The structural metrics ecological relevance (i.e. their relationship with the actual ecological processes taking place in the landscape) is often unproven and questionable (Kupfer, 2012). Conversely, actual connectivity gives very detailed information on the landscape but requires a large amount of 
Author-produced version of the article published in Ecological Indicators, 2018, N ${ }^{\circ} 89$, p.543-551.

The original publication is available at https://www.sciencedirect.com

Doi: 10.1016/j.ecolind.2018.01.068

data, and consequently hinders its implementation at larger scales. Thus, potential connectivity metrics seem to be a sound compromise for providing reasonable estimates of functional connectivity, i.e. species behavioural responses to landscape patterns (Kindlmann and Burel, 2008), while being applicable at large-scale due to low data requirements.

One promising landscape potential connectivity metric at large-scale is the metapopulation capacity $\lambda$ derived from metapopulation theory (Hanski and Ovaskainen, 2000). Hanski and Ovaskainen defined the metapopulation as a group of spatially separated populations of the same species interconnected by dispersal. In particular, the metapopulation capacity $\lambda$ measures how a given spatial configuration of a set of fragments contributes to the long-term persistence of a particular species structured as metapopulation. This indicator has been widely used to estimate the fragmentation effects in various landscapes, e.g. agricultural landscapes (Hietala-Koivu et al., 2004), forest landscapes (Pardini et al., 2010; Schnell et al., 2013a), or fluvial landscapes (Bertuzzo et al., 2015), and it has also been tested and explored further on simulated landscapes (Grilli et al., 2015; Rybicki and Hanski, 2013). Although the metapopulation capacity $\lambda$ may be a promising indicator of landscape fragmentation, for now its use is limited to specific local landscapes. The aim of this paper is to develop an easily appropriable and parsimonious methodology to derive worldwide regionalised fragmentation indexes based on $\lambda$ and to demonstrate the applicability and interest of this methodology with a dispersal distance of $1 \mathrm{~km}$ fitting a wide variety of species on all forest ecoregions in the biodiversity hotspots (Myers et al., 2000; Russell A. Mittermeier et al., 2004) as they are the richest and the most threatened plant and animal life reservoirs on Earth (Conservation International, 2016). This preliminary assessment will provide a global overview of the current abilities of birds or mammals with dispersal distances around $1 \mathrm{~km}$ to persist in the hotspots, which can be very useful in 
environmental assessment studies such as ones conducted in LCA or in footprint analyses. The innovative methodology itself also opens up vast prospects for biological conservation: with specific parameters adapted to a particular species in a specific region, its use could be extended to land use planning and areas prioritisation for both ecological protection and restoration.

\section{Materials and methods}

We used spatially explicit metapopulation models (Hanski, 1998; Hanski and Ovaskainen, 2000; Ovaskainen and Hanski, 2001) to describe habitat fragmentation at regional scales (e.g. ecoregion scale), since the metapopulation capacity $\lambda$ can conveniently be used to rank different fragmented landscapes in terms of their capacity to support viable metapopulations. This section will present 1) the conventional metapopulation capacity calculation at the landscape scale and then 2) a methodology to extend it to large regions.

\subsection{Metapopulation capacity of a species in a single landscape}

138 Formally, in metapopulation theory, metapopulation capacity $\lambda$ is given by:

$$
\text { Leading eigenvalue } \lambda \text { of matrix } \boldsymbol{M} \text { with elements } m_{i j}=\left\{\begin{array}{r}
A_{i}^{x} A_{j}^{y} f\left(d_{i j}\right), i \neq j \\
0, i=j
\end{array}\right.
$$

140 Where $A_{i}$ and $A_{j}$ are respectively the areas of fragments $i$ and $j, d_{i j}$ is the Euclidian distance

141 between the centroids of fragments $i$ and $j$, and $f\left(d_{i j}\right)$ is a dispersal function describing how the 142 species arrival rate drops off with the distance $d_{i j}$ between fragments. The exponents $x$ and $y$ are 143 scaling factors for the fragment area that depend on the extinction rate, the immigration rate and

144 the emigration rate. The function $f\left(d_{i j}\right)$ commonly presented is a negative exponential $e^{-\alpha d_{i j}}$, in 145 which $\alpha$ is the inverse of the species average dispersal distance. We adopted the following 146 exponential dispersal kernel with a cut-off at 0.01 (equation 2) proposed by Hanski et al. (2013): 


$$
f\left(d_{i j}\right)=\max \left\{e^{-\alpha d_{i j}}, 0.01\right\}
$$

148 Nevertheless, in original metapopulation models, colonisation is defined as a between-patch movement and there is no colonisation from a patch to itself. As a consequence, the original metapopulation capacity $\lambda$ of a single patch - no matter how large it is, and even if the whole patches, Schnell et al. (2013b) recently adapted the original metapopulation model by adding a self-colonisation component that gives large patches the potential to harbour small numbers of survivors following an extinction event which will be able to recolonise the rest of the patch. In the model with self-colonisation, $m_{i j}=A_{i}^{x} A_{j}^{y}$ when $i=j$. Consequently, with the selfcapacity and subsequent fragmentation decreases the metric. Like $\lambda, \lambda_{\text {self }}$ is a measure that combines overall area and fragmentation, and provides a consistent relative ranking of landscapes.

\subsection{Computing statistics on $\lambda_{\text {self }}$ calculated at the grid square scale for a large region}

For the environmental assessment of human activities, baseline indicators on regional habitat fragmentation would be useful for decision-making along globalised supply chains (i.e. along product or service life cycles). However, the metapopulation capacity should be quantified at a scale that is relevant for the focal species. According to Olson et al. (2001), the ecoregion average area is about $150,000 \mathrm{~km}^{2}\left(\right.$ median $\left.\approx 60,000 \mathrm{~km}^{2}\right)$ while the biodiversity hotspots have a mean surface area around $800,000 \mathrm{~km}^{2}$ (median $\approx 300,000 \mathrm{~km}^{2}$ ). Given that the sizes of these biogeographic units are both much larger than the model species dispersal abilities, it would be 
Thus, to compute $\lambda_{\text {self }}$ for larger areas, we divided the entire region of interest by a virtual grid and calculated $\lambda_{\text {self,GS }}$ for selected Grid Squares (GS) (see Figure A1 in Appendix A). The landscape structure was characterised by a nonhabitat matrix surrounding native habitat fragments. Using Q-GIS (QGIS Development Team, 2017), the habitat fragment centroids were identified, and the data necessary to calculate $\lambda_{\text {self,GS }}$ were extracted, i.e. each fragment size $A_{i}$, and its centroid coordinates $X_{i}, Y_{i}$. The distances $d_{i j}$ between the fragment centroids within each grid square were calculated, then, by introducing the dispersal distances of the modelled species, $\lambda_{\text {self,GS }}$ was calculated according to equation 1 (see Appendix A, Section 1-E for programming 178 details).

\subsection{Deriving fragmentation indexes for large regions based on $\lambda_{\text {self,GS }}$ statistics}

180 Statistical analysis of $\lambda_{\text {self,GS }}$ values calculated at the grid square scale can be used to obtain

181 fragmentation indexes for a whole region.

182 Several studies support the hypothesis that fragmentation effects follow a threshold function related to the remaining available habitat. When habitat area is still large enough, fragmentation can have a positive impact, i.e. by increasing the local species richness, but which will be hidden by the superior, negative habitat loss effects. When the habitat area falls below a critical threshold, generally around 20-30\% (Andren, 1994; Flather and Bevers, 2002; Hanski, 2015; Pardini et al., 2010; Schneider, 2001), the fragmentation effects become negative, affecting species survival, and should not be ignored. Consequently, $\lambda_{\text {self,GS }}$ were exclusively derived for grid squares with less than $30 \%$ of their original vegetation (defined as Conditions of $\lambda_{\text {self }}$ validity others, grasslands, savannas, forests, or deserts). In this study, only primary forest ecosystems

192 were considered and $\lambda_{\text {self,GS }}$ was not calculated for grid squares with no primary forest at all. 
Author-produced version of the article published in Ecological Indicators, 2018, N89, p.543-551.

The original publication is available at https://www.sciencedirect.com

Doi: 10.1016/j.ecolind.2018.01.068

Based on $\lambda_{\text {self,GS }}$ values of all grid squares in which forest cover ranges from $>0 \%$ to $\leq 30 \%$

194 thereafter referred to as 'highly converted forest' - , we can determine a median value $\lambda_{\text {self;j }}$ of the non-normally distributed $\lambda_{\text {self,GS }}$ (Figure A2 in Appendix A), that stands for the metapopulation

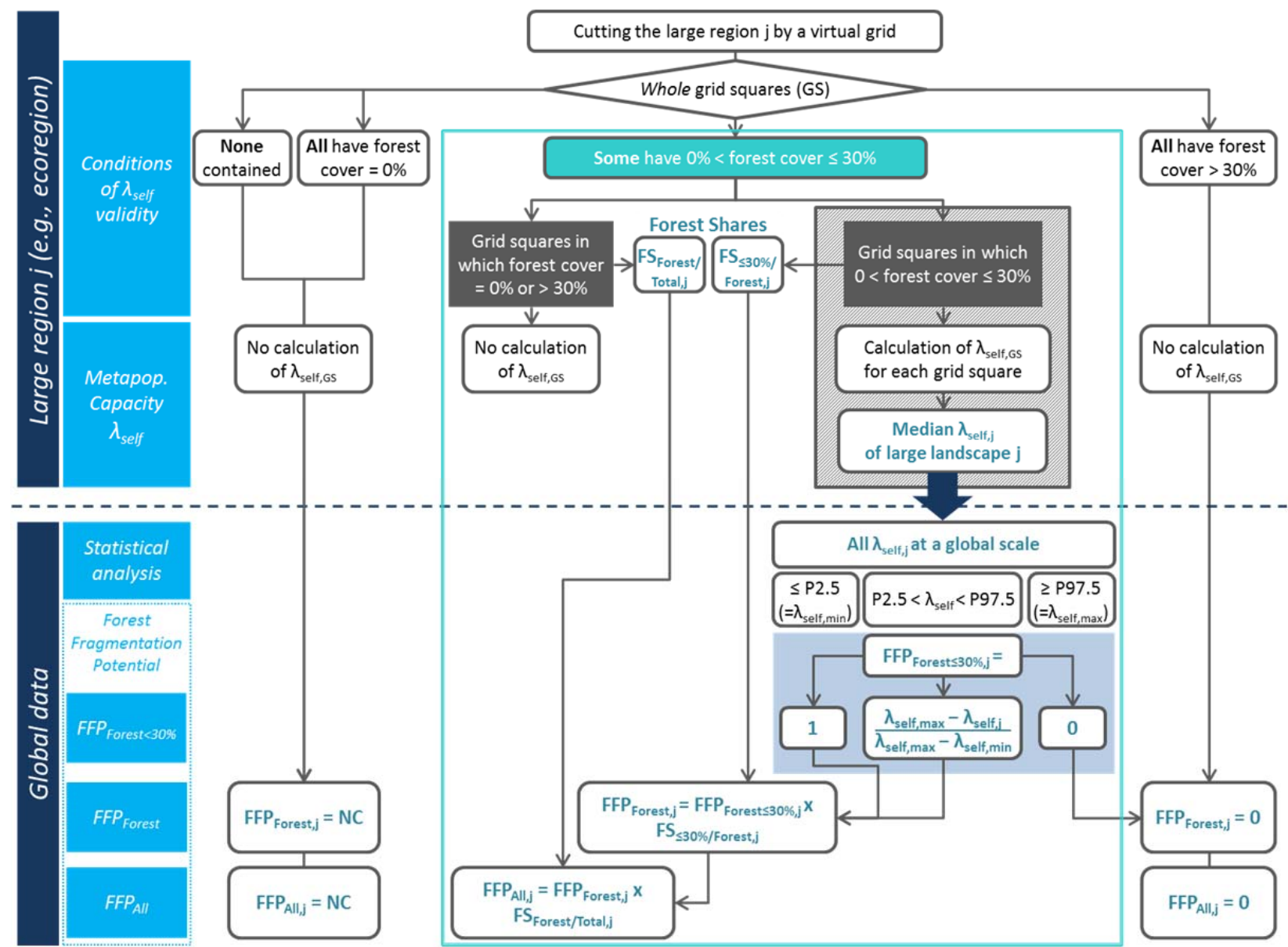

199 Figure 1: Methodology for calculating the fragmentation indexes (Forest Fragmentation

200 Potential FFP) of a large region at three levels of spatial aggregation (highly converted forest,

201 forest and the entire region). P: Percentile. NC: Not calculated.

Once $\lambda_{\text {self }, j}$ has been computed for each large region $j$ (e.g. ecoregions), the median values of all

203 large regions are ranked from the $2.5^{\text {th }}$ percentile $(\mathrm{P} 2.5)$ to the $97.5^{\text {th }}$ percentile (P97.5). 
Subsequent winsorising reduces the effect of possible outliers by limiting extreme values in the data via setting outliers to a data specified percentile. Here, a 95\% winsorising was applied, meaning that all data below the $2.5^{\text {th }}$ percentile are set equal to the $2.5^{\text {th }}$ percentile $\left(=\lambda_{\text {self,min }}\right)$ and all data above the $97.5^{\text {th }}$ percentile are set equal to the $97.5^{\text {th }}$ percentile $\left(=\lambda_{\text {self,max }}\right)$. A $95 \%$ winsorising was found to deal adequately with extreme values without being too exclusive on the dataset. Normalisation from 0 (low fragmentation stress) to 1 (high fragmentation stress) provides a commensurable and dimensionless index, i.e. the Forest Fragmentation Potential of highly converted forests $F F P_{\text {Forest } \leq 30 \%, j}$ of a large region $j$ according to equation 3 . In this way, 212 the $5 \%$ extreme values of the global dataset, i.e. the least fragmented regions $\left(\lambda_{\text {self }} \geq\right.$ P97.5) and 213 the most fragmented regions $\left(\lambda_{\text {self }} \leq\right.$ P2.5), have a Forest Fragmentation Potential set to 0 and 1 , 214 respectively. In between, the fragmented regions are classified according to their fragmentation 215 degree.

$216 F F P_{F o r e s t \leq 30 \%, j}$ indicates the fragmentation 'state' of the most critical forest areas within region

$217 j$. The more region $j$ is fragmented, the smaller is $\lambda_{\text {self }, j}$ and the higher is $F F P_{\text {Forest } \leq 30 \%, j}$ :

$$
\text { FFP } P_{\text {Forest } \leq 30 \%, j}=\frac{\left(\lambda_{\text {self }, \text { max }}-\lambda_{\text {self }, j}\right)}{\left(\lambda_{\text {self }, \text { max }}-\lambda_{\text {self }, \text { min }}\right)}
$$

219 To characterise the Forest Fragmentation Potential of the whole region $F F P_{F o r e s t}, j$, we weight $220 F F P_{\text {Forest } \leq 30 \%, j}$ by the proportion between the highly converted forest grid squares and the total number of forest grid squares in region $j F S_{\frac{\leq 30 \%}{\text { FOREST }}}$;

$$
F F P_{\text {Forest }, j}=F F P_{\text {Forest } \leq 30 \%, j} \times F S_{\frac{\leq 30 \%}{\text { FOREST }}, j}
$$

$$
\text { With } F S_{\frac{\leq 30 \%}{\text { FOREST }}, j}=\frac{\sum \mathrm{GS}, \text { with } 0 \%<\text { forest cover } \leq 30 \%}{\sum \mathrm{GS}, \text { with } 0 \% \text { with }<\text { forest cover } \leq 100 \%}
$$

224 Finally, to determine the whole region fragmentation state, we use the regional forest area 225 proportion, defined as the ratio of forest grid squares and total number of grid squares (i.e. 
including forest-free grid squares) in the region $\left(F S_{\frac{\text { FOREST }}{\mathrm{TOTAL}}, j}\right.$ in equation 5). The Forest region $j$ (e.g. an ecoregion):

$$
F F P_{A l l, j}=F F P_{\text {Forest }, j} \times F S_{\frac{\text { FOREST }}{\text { TOTAL }}, j}
$$

$$
\text { With } F S_{\frac{\text { FOREST }}{\text { TOTAL }}, j}=\frac{\sum \mathrm{GS}, \text { with } 0 \%<\text { forest cover } \leq 100 \%}{\sum \mathrm{GS}}
$$

\subsection{Implementing the methodology on forest ecoregions included in the biodiversity}

\section{hotspots}

For a global implementation, we first focus our assessment on the biodiversity hotspots. To

qualify as a biodiversity hotspot, a region must meet two criteria, i.e. 1) holding high numbers of endemic vascular plants, and 2) having $30 \%$ or less of its original vegetation (Conservation International, 2016), thus corresponding to the 'fragmentation threshold' mentioned above, below which considering fragmentation is relevant. Furthermore, Sloan et al. (2014) recently provided updated estimates of natural, intact vegetation within these hotspots that show that their state could be even more critical than previously described. We considered all ecoregions included in the biodiversity hotspots with a focus on forest major habitat types (see Appendix A,

241 Section 1-B for more details). Area loss in forests is rarely simply the removal of contiguous areas and these habitats are particularly experiencing fragmentation (Whitmore and Sayer, 1992), mainly because of industrial timber extraction, agricultural expansion, fire, and resource

244 extraction (Potapov et al., 2017). Due to fragmentation, the number of intact forest landscapes 245 (larger than $500 \mathrm{~km}^{2}$ ) is decreasing drastically, around 7\% in 13 years, particularly in tropical 246 regions (Potapov et al., 2017). Thus, forests are under pressure like never before, while they host 90\% of terrestrial species (WWF, 2016b). 
We applied the methodology developed (Figure 1Figure 1) to all biodiversity hotpots that contain forest ecoregions (i.e. 34 forest hotspots: six in Africa, fourteen in Asia-Pacific, four in Europe and Central Asia, five in North and Central America, and five in South America). 259 ecoregions met the conditions for $\lambda_{\text {self,j }}$ calculation (see Conditions of $\lambda_{\text {self }}$ validity in Figure 1Figure 1), and $F F P_{j}$ were provided for a total of 283 ecoregions, because fragmentation indexes of the 24 ecoregions for which all whole grid squares had a forest cover higher than $30 \%$ were set to 0 (see right side of Figure 1Figure 1). Details on spatial processing can be found in Appendix A, Section 1-D.

\subsection{Input data for model parameters}

Two kinds of data are required to implement the developed methodology, i.e. 1) species characteristics (dispersal ability and scaling factors), and 2) landscape inputs (original habitat choice, map resolution, and grid size for spatial analysis). For each of them, data constraints and availability are discussed to select the most appropriate data for the $\lambda_{\text {self }}$ global calculation (Table habitat, a species can be heavily or slightly affected depending on its ability to move $(1 / \alpha$, in connection with $d_{i j}$ ), and on its immigration and extinction abilities ( $x$ and $y$, related to $A_{i}$ ). Various 'dispersal distances' are reported in literature, e.g. the median, mean and maximum dispersal distances, and the migratory distance. The differences between these variables are hard to capture because their calculation varies depending on the author. Furthermore, there is a large variability associated with species dispersal distances, depending on their size or migratory 269 habits. Based on a literature review of available species dispersal distances (Sutherland et al., 270 2000), we arbitrarily considered a $1 \mathrm{~km}$ dispersal distance, which can apply to some birds and 
Author-produced version of the article published in Ecological Indicators, 2018, N ${ }^{\circ} 89$, p.543-551.

The original publication is available at https://www.sciencedirect.com

Doi: 10.1016/j.ecolind.2018.01.068

mammals, as a first example of the methodology application. Regarding scaling factors $x$ and $y$, Hanski et al. (2013) give a $x$ realistic value for birds and mammals (1.5), while Schnell et al. (2013b) propose another value valid for many taxa (0.5). Both studies considered a $y$ value of 1 .

274

We used the values provided by Schnell et al. (2013b) because they offer a broader choice in terms of applications to different taxa.

The fragmentation assessment strongly depends on the land cover of interest definition (Riitters et al., 2000). In this work, we used Globcover 2009 maps (Bontemps et al., 2011), produced by the European Space Agency, which count 22 land cover classes. Among them, several classes can be included in the forest definition, and considering only class 50 Closed (>40\%) broadleaved deciduous forest $(>5 \mathrm{~m})$, both classes 50 and 40 Closed to open (>15\%) broadleaved evergreen or semi-deciduous forest $(>5 \mathrm{~m})$, or all eight potential forest classes combined, can have a large influence on the results, underestimating or overestimating the real forest cover. Furthermore, reports usually describe the remaining original habitat area in percentage 'of its original extent' (CEPF, 2016; Di Bitetti et al., 2003), but all the ecoregion was not necessarily covered with this original habitat (other land covers, water bodies, mountains, etc.). To simplify our methodology, we considered all Globcover 2009 forest classes.

Map resolution is also a crucial parameter, since the notion of 'fragment' strongly depends on the scale considered. Many metrics indicated lower fragmentation at coarser spatial resolutions (Saura, 2004), and a recent study showed that metapopulation capacity is sensitive to the spatial scale at which the habitat units were defined (Blazquez-Cabrera, 2014). Maps with smaller resolutions identify more non-forest area where forest cover is dominant but not exclusive. Hanski et al. (2013) used a map resolution of $30 \mathrm{~m}$, but they used a bird species dispersal distance much smaller $(300 \mathrm{~m})$ than the median value found in literature, i.e. $4 \mathrm{~km}$ for birds 
(Sutherland et al., 2000). A transposition based on ecological parameters would lead to a scaleup of a factor ten for map resolution (400 m). Thus, we took Globcover 2009 (300 m resolution) for land cover data.

297 Likewise, fragmentation can turn out greater when larger grid sizes are used (Riitters et al.,

298 2000). Consequently, to perform a meaningful metapopulation capacity calculation, it is essential to define spatial scale(s) at which metapopulation processes predominantly take place. Olson et al. (2001) examined a moth metapopulation with a measured dispersal distance of $100 \mathrm{~m}$ at four levels of spatial analysis and concluded that metapopulation processes were important at the regional and sub-regional scales (i.e. $\approx 35 \mathrm{~km}^{2}$ and $\approx 10 \mathrm{~km}^{2}$, with $100 \mathrm{~m}$ and $50 \mathrm{~m}$ resolutions respectively). Consequently, for dispersal distances ranging from $500 \mathrm{~m}$ to $5 \mathrm{~km}$, spatial scales between 50 and $2000 \mathrm{~km}^{2}$ would be consistent, with associated resolutions ranging from $250 \mathrm{~m}$ to $5 \mathrm{~km}$. Following the same logic as for map resolution, we could also have scaled-up the grid size for $\lambda_{\text {self }}$ calculations based on Hanski et al. (2013), but we found $100 \mathrm{~km}^{2}$ more adapted to the range of ecoregion sizes. $1000 \mathrm{~km}^{2}$ grid squares were too large to adequately reflect some small ecoregions, e.g. for the Montane Fynbos And Renosterveld ecoregion (AT1203), only three grid squares were larger than $950 \mathrm{~km}^{2}$, representing only $6 \%$ of the whole ecoregion area. Thus, a $100 \mathrm{~km}^{2}$-grid was applied to each hotspot, and grid squares larger than $95 \mathrm{~km}^{2}$ (5\% margin) were selected for each ecoregion. Consequently, all ecoregions smaller than the grid square size $\left(100 \mathrm{~km}^{2}\right)$ were excluded from the outset, representing less than $0.2 \%$ in surface of all forest ecoregions belonging to the biodiversity hotspots.

\section{Results}

\subsection{Spatial representation of the three FFPs}


Author-produced version of the article published in Ecological Indicators, 2018, N ${ }^{\circ} 89$, p.543-551.

The original publication is available at https://www.sciencedirect.com

Doi: 10.1016/j.ecolind.2018.01.068

The FFPs of all 30 ecoregions included in the Indo-Burma hotspot are spatially represented for each $100-\mathrm{km}^{2}$ grid square included in the hotspot (Figure 2Figure 4). $F F P_{\text {Forest } \leq 30 \%, j}$ is a median value of the most critical forest areas fragmentation 'state' within the ecoregion $j$, thus only grid squares in which forest cover is smaller than $30 \%$ are concerned (upper-map in Figure 2Figure 4). $F F P_{\text {Forest } \leq 30 \%}$ can be used to assess the potential impact on biodiversity of a current or future activity using land in a highly converted forest area. As $F F P_{\text {Forest }}$ weights the previous index by the total forest cover in the ecoregion, the index value is affected to all forest grid squares (middle-map in Figure 2Figure 4). $F F P_{\text {Forest }}$ can be used to compare activities for which land use surely occurs in a forest area, with no additional information on the forest cover. Lastly, $F F P_{A l l}$ applies to all grid squares in the ecoregion (lower-map in Figure 2Figure 4) and can be used to rank land use impacts in different ecoregions when the exact locations of activities in the ecoregions are unknown. The more spatially aggregated the fragmentation indexes (from $F F P_{F o r e s t \leq 30 \%}$, then $F F P_{\text {Forest }}$, to finally $\left.F F P_{A l l}\right)$, the more uncertain they are.

More explanations on the different indexes are given with the example of the Indo-Burman ecoregions A, B and C (Figure 2Figure 4). All three ecoregions have a high $F F P_{\text {Forest } \leq 30 \%}$ (respectively $0.92,0.82$ and 0.99 ), which means that their most converted forest zones are highly fragmented and have a strong negative impact on species (compared to other ecoregions worldwide). Overall forest, however, is less damaged in ecoregion B than in ecoregions A or C, i.e. grid squares with less than $30 \%$ of forest are scarcer in ecoregion $\mathrm{B}$, so $F F P_{\text {Forest }, B}(0.10)$ is much lower than $F F P_{\text {Forest, } A}(0.56)$ or $F F P_{\text {Forest }, C}(0.86)$. However, almost all $100 \mathrm{~km}^{2}$ grid squares contain forest in both ecoregions $\mathrm{A}$ and $\mathrm{B}$ whereas ecoregion $\mathrm{C}$ contains many forestfree grid squares, so $F F P_{A l l, A}(0.54)$ and $F F P_{A l l, B}(0.10)$ are close to $F F P_{F o r e s t, A}$ and $F F P_{F o r e s t, B}$ whereas $F F P_{A l l, C}(0.18)$ decreases considerably compared to $F F P_{\text {Forest, } C \text {. }}$ 

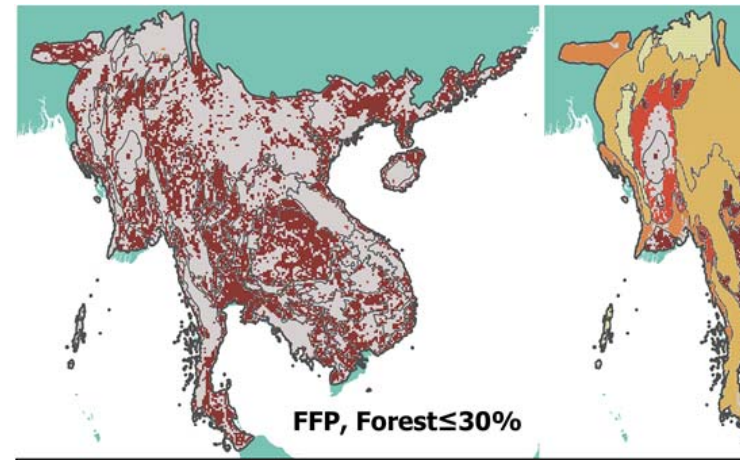

Forest Fragmentation Potential (FFP)

$0.0-0.2$

$0.2-0.4$
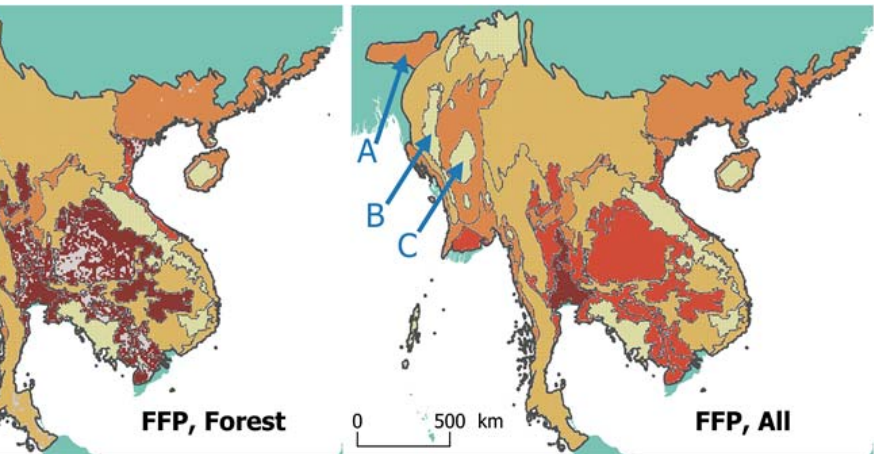

339

Figure 2: Fragmentation indexes for forest ecoregions included in the Indo-Burma biodiversity

hotspot calculated for a species dispersal distance of $1 \mathrm{~km}$; arrow A points to Meghalaya

Subtropical Forests (ecoregion IM0126), arrow B points to Chin Hills-Arakan Yoma Montane

Forests (ecoregion IM0109), and arrow C points to Irrawaddy Dry Forests (ecoregion IM0205)

\subsection{Global maps of FFPs}

345 The fragmentation indexes were calculated for each forest ecoregion included in the 34

346 biodiversity hotspots for an illustrative species dispersal distance of $1 \mathrm{~km}$. Global map of $F F P_{\text {All }}$

347 is presented in Figure 3Figure 3, and equivalent maps for $F F P_{\text {Forest } \leq 30 \%}$ and $F F P_{\text {Forest }}$ are

348 displayed in Figure A3 and Figure A4 in Appendix A. All raw data for $F F P_{\text {Forest }<30 \%}, F F P_{\text {Forest }}$

349 and $F F P_{A l l}$ can be found in Appendix B (separate Excel file). 


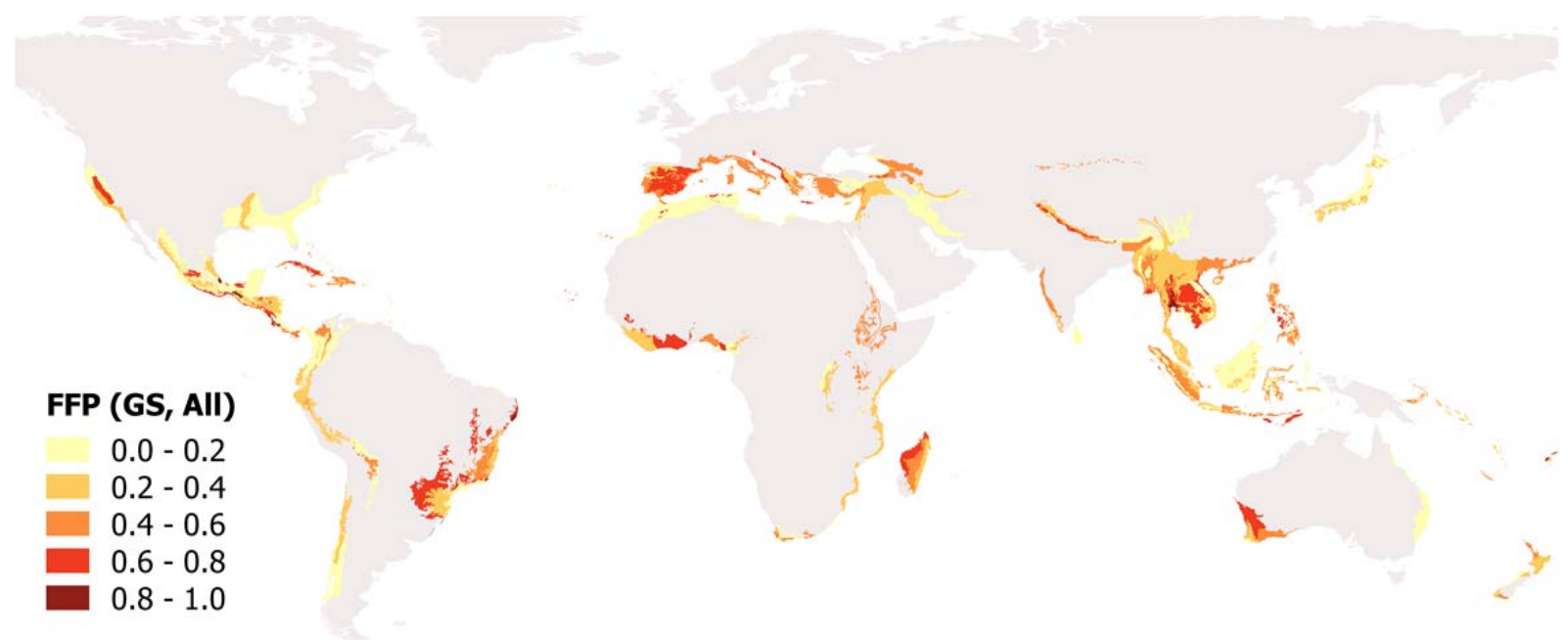

351 Figure 3: Forest Fragmentation Potential $F F P_{A l l}$ for all forest ecoregions included in the 352 biodiversity hotspots (coloured areas) calculated for a species dispersal distance of $1 \mathrm{~km}$

353 The most converted forests within the ecoregions (i.e. $0 \%<$ forest cover $\leq 30 \%$ ) globally show 354 a high fragmentation potential (Figure A3 in Appendix A). Only 42 out of the 259 ecoregions for 355 which $\lambda_{\text {self }}$ was calculated have a fragmentation potential $F F P_{\text {Forest } \leq 30 \%}$ smaller than 0.6 , and 57 356 ecoregions (mainly in the Palearctic and Indomalayan realms) have it higher than 0.95. 357 However, $F F P_{\text {Forest } \leq 30 \%}$ reflects the fragmentation potential of already altered forest areas, and 358 does not reflect the forest 'state' of the whole ecoregion.

$359 \quad F F P_{\text {Forest }}$, i.e. $F F P_{\text {Forest } \leq 30 \%}$ weighted by the proportion of highly converted forest zones 360 compared to all forest zones, provides more distributed results globally (Figure A4 in Appendix 361 A). Only 22 ecoregions, mainly in Indo-Burma, Mediterranean Basin and Irano-Anatolian 362 hotspots, present $F F P_{\text {Forest }}$ higher than 0.90. In addition, there are strong differences between $363 F F P_{\text {Forest } \leq 30 \%}$ and $F F P_{\text {Forest }}$ results (respective median values of 0.86 and 0.27 ), which indicate 364 that fragmentation is most frequently a process confined to relatively specific geographical areas. 365 For instance, some ecoregions have highly fragmented forests (high $F_{F P} P_{\text {Forest } \leq 30 \%}$ ), but only over 
366 a small part of their total forest area (low FFP Forest). The spatial aggregation at the ecoregion scale tends to smooth the results.

$368 F F P_{A l l}$, weighted in proportion to ecoregion forest areas, has values very similar to $F F P_{F o r e s t}$

369 (global median of 0.23$)$. This is because there are few landscapes (100 $\mathrm{km}^{2}$ grid squares) with no

370 forest at all (i.e. the forest share $F S_{\frac{\mathrm{FOREST}}{\mathrm{TOTAL}}}$ often approaches 1 ), which is expected for ecoregions

371 with forest as major habitat types. Nevertheless, for some ecoregions, e.g. for the four North

372 African ecoregions included in the Mediterranean Basin hotspot, FFP Forest can be high and

373 FFP $_{\text {All }}$ much lower, due to their small forest cover. Conversely, e.g. in Indonesia or South

374 America, both $F F P_{\text {Forest }}$ and $F F P_{\text {All }}$ can be high because of some ecoregions large forest share.

375 Only three ecoregions have $F F P_{\text {All }}$ higher than 0.9 , and they all are in the Neotropical realm

376 (ecoregions NT0233 Veracruz Dry Forests, NT0102 Atlantic Coast Restingas and NT0151

377 Pernambuco Coastal Forests). 


\section{Discussion}

An easily appropriable and performing methodology to derive worldwide regionalised $\lambda$-based

381 fragmentation indexes at meaningful scales for fragmentation mechanisms was built, and applied

382 to an illustrative, arbitrary example (by setting the species dispersal distance to $1 \mathrm{~km}$, and using

383 scaling factors adapted to birds or mammals). The objective was twofold: (1) to test the

384 feasibility of the method at a worldwide scale, and (2) to evaluate the resulting indexes' ability to provide valuable information on fragmentation stresses. The methodology was successfully applied in about 300 ecoregions all over the world, and the resulting indexes clearly confirmed significant intra- and inter-ecoregions differences regarding landscapes' fragmentation stresses. These results open up prospects for promising applications of the methodology to real ecological studies. However, the proposed methodology still faces some methodological and practical

390 limitations and still has room for improvement.

\subsection{Metapopulation model limitations}

The interest of metapopulation theory to explain variations in species occurrence patterns in highly fragmented landscapes has been recognised. However, metapopulation theory implies that

394 the populations exist in patchy distributions. When there is no evidence for metapopulation

395 dynamics in a given species or region, this approach might not be valid. As a great range of 396 dispersal models are available in the literature, the more adapted and realistic dispersal functions $397 f\left(d_{i j}\right)$ should be incorporated in spatial models when possible (Travis and French, 2000). In the 398 proposed methodology, due to the metapopulation model flexibility, other more complex dispersal functions could easily replace the proposed one if needed. Furthermore, because 
species dispersal still needs to be better understood and assessed, new ecological developments and data could also be easily incorporated in the model as soon as they become available. metapopulation models have historically treated a landscape as a collection of habitat patches in our case, forest - separated by a homogenous, permeable but unsuitable habitat usually called matrix - in our case, non-forest-. In these models, movement between patches depends only on the distance between patches and the inherent species dispersal ability, and the matrix structure and quality effects on movement through the landscape are neglected. Yet, even if theoretical 408 and empirical evidence show that matrix quality can be extremely important in determining 409 metapopulation dynamics (Vandermeer and Carvajal, 2001), these factors are rarely incorporated 410 into metapopulation models. In particular, linear infrastructure such as road networks can 411 considerably hinder species movements (often referred to as the 'barrier effect' in ecology 412 (Forman and Alexander, 1998)) and have a strong negative impact on species (Loro et al., 2015). 413 Moreover, this barrier effect varies among species, which are not similarly affected by a given 414 barrier. Gebauer et al. (2013) investigated the importance of matrix type for metapopulation modelling and found that it had as much or sometimes more influence than patch sizes or 416 distances between patches on metapopulation parameters. The use of mathematical tools enabled 417 by the matrix-modelling framework, such as sensitivity and elasticity analyses (Shima et al., 418 2010), or the incorporation of a matrix resistance parameter, which is expected to vary among 419 species (Ricketts, 2001), could definitively improve metapopulation modelling. If matrix quality 420 was to be included in the metapopulation model, complementary road maps could be used in 421 addition to Globcover 2009 maps to capture the barrier effects induced by linear infrastructure. 
Finally, the metapopulation capacity assesses species persistence in fragmented landscapes, which is a limited aspect of all possible ecological attributes and levels of biodiversity organisation, which encompasses not only species composition but also ecosystem structure and functions.

\subsection{Data availability and uncertainty}

There is inherent uncertainty in data (e.g. land cover maps, species dispersal distances), on choices associated with data treatment, and on the metapopulation model itself, i.e. to what extent does it reflect real species behaviour. The results should hence be interpreted in light of this information (Langford et al., 2006). Globcover 2009 maps are among the most detailed, reliable and up-to-date global land cover maps. Their overall accuracy weighted by the class area reaches $67.5 \%$. The Globcover 2009 resolution $(300 \mathrm{~m})$ is consistent with the spatial scale considered (i.e. global statistics on $100 \mathrm{~km}^{2}$-landscapes), and execution times for the associated spatial processing are acceptable. Regarding species data, the selected dispersal distances were chosen to be of the same order of magnitude than estimates derived from empirical data from a global literature review (Sutherland et al., 2000). The uncertainty associated with these estimates is very closely linked to the natural data variability. A way to overcome this shortcoming would be to generate more results to cover a more complete range of species dispersal distances. As more biodiversity monitoring data will become available, these dispersal distances estimates should be updated and results accuracy will be improved. Moreover, the indexes could be combined with data on specific species effectively inhabiting each ecoregion to enhance the

442 results relevance. Another interesting development would be to weight the indexes by the 443 threatened status and/or the level of species endemism, e.g. percent endemism by taxonomic 444 group in each hotspot (CEPF, 2016). 
The $\lambda_{\text {self }}$ sensitivity to several crucial parameters related to 1 ) land cover data (original habitat and maps resolution), 2) grid size, and 3) species data (dispersal distance and scaling factor $x$ ) was assessed and the results can be found in Appendix A, Section 3-A. Other data or methodological choices likely to affect the results were also discussed in the same section. However, even if some parameters may have a great influence on $\lambda_{\text {self, }}$ no change in these will affect their ranking (i.e. for ecoregions ranking). The $\lambda_{\text {self }}$ final distribution and subsequent $F F P$ indexes derived from $\lambda_{\text {self }}$, might be affected though, given that the $\lambda_{\text {self }}$ dependency on the input parameters and choices is not necessarily linear.

Regarding the fragmentation index calculation based on $\lambda_{\text {self }}$ statistics, the $\lambda_{\text {self,GS }}$ values aggregation for large regions (e.g. ecoregions), by means of the median, is another important source of uncertainty, due to the intra-ecoregion spatial variability. As an example, the $\lambda_{\text {self,GS }}$ spatial variability of the larger forest ecoregion included in the biodiversity hotspots, i.e. Alto Paraná Atlantic Forest (ecoregion NT0150), is illustrated in Figure A5 in Appendix A. The results show that, rather than being distributed evenly throughout the ecoregion, fragmentation can be very critical in some specific places of the ecoregion. Similarly to other stress indexes

460 (e.g. water stress), a global or regional fragmentation stress can strongly differ from a local 461 stress, and too aggregated stress values will be unrepresentative of the local reality.

462 Likewise, the definition and spatial resolution of Forest Shares FS used for FFP calculation may influence the results and is discussed in Appendix A, Section 3-C.

\subsection{Applicability}

The fragmentation indexes can be used directly to rank all highly fragmented forest ecoregions

466 included in the biodiversity hotspots. As they are based on metapopulation capacity, which is 467 already a relative measure, and given their strong sensitivity to the input parameters, the 
fragmentation indexes should not be taken as absolute values and should be used for comparative purposes only. Assuming that the species dispersal ability is known and similar in magnitude to the considered dispersal distance, conclusions can be drawn for this particular species. However,

471 for now, they are limited to a specific range of species dispersal distances, based on animal dispersal abilities statistics. Plants should also be considered, especially as metapopulation concept has been largely applied to plants through seed dispersal (Verheyen et al., 2004).

To overcome this problem, the proposed grid procedure and methodology for deriving metapopulation capacity statistics at regional scales was designed to be easily used and applied to other large datasets. Our analysis was restricted to biodiversity hotspots as defined by Myers et al. (2000), but other prioritisation approaches exist for global biodiversity conservation, and other templates may be considered (Brooks et al., 2006; Moran and Kanemoto, 2017). We also focused the scope of application on the ecoregions whose major habitat type was forest (i.e. approximately $70 \%$ in surface of all ecoregions belonging to the biodiversity hotspots), but other major habitat types, e.g. grasslands, could easily be incorporated. Conversely, the proposed methodology could also be applied to specific ecoregions or sub-ecoregions, with a grid size and calculation program is available upon request.

\subsection{Conclusions and perspectives}

The global forest fragmentation is a critical issue facing major challenges for the biodiversity conservation and ecosystems management, particularly in tropical environments (Bregman et al., 2014), and especially since these effects may be worsened by other global changes caused by human activity, e.g. climate change (Haddad et al., 2015). Macro-scale conservation planning 
gives a means of coping with the challenge arising from the environmental impacts of extensive land use changes for urban or agricultural activities (Olsoy et al., 2016). To this end, global information on areas sensitive to fragmentation is needed to improve the effectiveness of planning efforts.

Thus, an innovative methodology for modelling the fragmentation potential of large regions was proposed. The landscape spatial configuration is combined with a metapopulation model to obtain an ecologically relevant landscape fragmentation metric to compare any fragmented landscapes, producing an efficient tool for land management. The modelling approach applied in this work was developed to fit most species, provided that some adaptations are made to deal 500 with species specificities. Indeed, the flexibility of the methodology allows the spatial 501 parameters, e.g. the grid size and the map resolution, and the species parameters, e.g. the 502 dispersal distance and the dispersal function of the metapopulation model, to be easily adapted to 503 a specific species.

504 Secondly, as an example, we provide a first set of fragmentation indexes for ranking all forest ecoregions $\left(>100 \mathrm{~km}^{2}\right)$ belonging to the biodiversity hotspots. These global maps are relevant to the subset of species corresponding to the types of habitat and to the dispersal capacities considered, and provide first-hand information on the ability of these species, i.e. birds or mammals with a dispersal distance of $1 \mathrm{~km}$, to persist in highly fragmented habitats. These 509 indexes can help decision makers, from producers, scientists, conservationists, to governments, 510 to better target their actions. They can be used as a tool for land planners or industrial companies,

511 for comparing different options regarding their activities locations at the ecoregion scale.

512 Conversely, they enable focusing on areas where offset measures would have the most impact 513 (Dalang and Hersperger, 2012). Finally, fragmentation metrics at large-scale can be used to 

particularly, they could contribute to better assess the environmental impacts of a product using land at different places around the globe along its life cycle. To date, several indicators are available in LCA to quantify a certain number of land use impacts (e.g. the impact of decreasing their habitat quantity on species), but, until now, habitat fragmentation impacts are poorly considered. In this perspective, the fragmentation indicators should be calculated for each taxon usually considered for land use impacts in LCA, i.e. birds, mammals, reptiles, amphibians and

521 vascular plants, using median values of species or seed dispersal distances and scaling factors for 522 which estimates are available in the literature (see for example Kharouba et al. (2012); 523 Sutherland et al. (2000) and Verheyen et al. (2004)). They should also be extended to other 524 habitat types (e.g. grasslands, savannas, shrublands, tundra, mangroves and deserts). In addition, 525 as they stand, the fragmentation indexes are stand-alone indicators which are not directly linked to a land use intervention. Incorporating them into analytical environmental assessment methods such as LCA will need further development. 


\section{Appendices}

Appendix A: Additional methods and results (PDF)

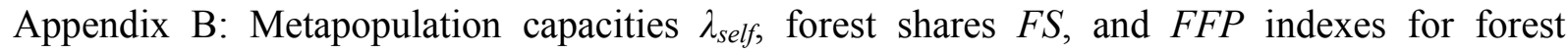
ecoregions included in the biodiversity hotspots for a $1 \mathrm{~km}$ species dispersal distance (XLSX)

\section{Acknowledgments}

534 The authors thank Jean-Louis Martin and Ana Rodrigues from CEFE, Montpellier for their 535 inspiring and valuable insights on the fragmentation issue, Thomas Koellner and Asja Bernd

536 from the University of Bayreuth, Germany for their useful inputs on the fragmentation

537 assessment, Jean-Baptiste Mihoub from Pierre and Marie Curie University, Paris for fruitful 538 discussions about global biodiversity assessment, and Samuel Alleaume from UMR TETIS,

539 Irstea Montpellier for his good advice on spatial processing. The authors are members of the

540 ELSA research group (Environmental Life Cycle and Sustainability Assessment, 541 http://www.elsa-lca.org/) and thank all ELSA members for their advice. This work was

542 supported by the French National Research Agency (ANR), the Occitanie Region, ONEMA,

543 Ecole des mines d'Alès and the industrial partners (BRL, SCP, SUEZ, VINADEIS, and

544 Compagnie Fruitière) of the Industrial Chair for Environmental and Social Sustainability 545 Assessment 'ELSA-PACT' (ANR grant no. 13-CHIN-0005-01). 
Author-produced version of the article published in Ecological Indicators, 2018, N89, p.543-551.

\section{References}

Andren, H., 1994. Effects of habitat fragmentation on birds and mammals of suitable habitat: a review landscapes with different proportions. Oikos 71, 355-366.

Atauri, J.A., de Lucio, J. V., 2001. The role of landscape structure in species richness distribution of birds, amphibians, reptiles and lepidopterans in Mediterranean landscapes. Landsc. Ecol. $16,147-159$.

Bertuzzo, E., Rodriguez-Iturbe, I., Rinaldo, A., 2015. Water Resources Research. Water Resour. Res. 51, 2696-2706. doi:10.1002/2015WR016946.Received

Blazquez-Cabrera, S., 2014. Indicators of the impacts of habitat loss on connectivity and related conservation priorities: Do they change when habitat patches are defined at different scales? Ecol. Indic. 45, 704-716. doi:10.1016/j.ecolind.2014.05.028

Bontemps, S., Defourny, P., Bogaert, E. Van, Arino, O., Kalogirou, V., Perez, J.R., 2011. GLOBCOVER 2009: Products Description and Validation Report.

Bregman, T.P., Sekercioglu, C.H., Tobias, J.A., 2014. Global patterns and predictors of bird species responses to forest fragmentation: Implications for ecosystem function and conservation. Biol. Conserv. 169, 372-383. doi:10.1016/j.biocon.2013.11.024

Brooks, T.M., Mittermeier, R.A., da Fonseca, G.A.B., Gerlach, J., Hoffmann, M., Lamoreux, J.F., Mittermeier, C.G., Pilgrim, J.D., Rodrigues, A.S.L., 2006. Global Biodiversity Conservation Priorities. Science (80-. ). 313, 58-61. doi:10.1126/science.1127609

Calabrese, J.M., Fagan, W.F., 2004. A comparison-shopper's guide to connectivity metrics. Front. Ecol. Environ. 2, 529-536. 
Author-produced version of the article published in Ecological Indicators, 2018, N ${ }^{\circ} 89$, p.543-551.

The original publication is available at https://www.sciencedirect.com

Doi: 10.1016/j.ecolind.2018.01.068

CEPF, 2016. Biodiversity Hotspots [WWW Document]. URL

http://www.cepf.net/resources/hotspots/ (accessed 12.19.16).

569

Chaudhary, A., Kastner, T., 2016. Land use biodiversity impacts embodied in international food trade. Glob. Environ. Chang. 38, 195-204. doi:10.1016/j.gloenvcha.2016.03.013

Conservation International, 2016. Biodiversity Hotspots [WWW Document]. URL http://www.conservation.org/How/Pages/Hotspots.aspx (accessed 12.19.16).

Convention on Biological Diversity, 2016. Aichi Biodiversity Targets [WWW Document]. URL https://www.cbd.int/sp/targets/ (accessed 12.16.16).

Crooks, K.R., Burdett, C.L., Theobald, D.M., Rondinini, C., Boitani, L., 2011. Global patterns of fragmentation and connectivity of mammalian carnivore habitat. Philos. Trans. R. Soc. 366, 2642-2651. doi:10.1098/rstb.2011.0120

Dalang, T., Hersperger, A.M., 2012. Trading connectivity improvement for area loss in patchbased biodiversity reserve networks. Biol. Conserv. 148, 116-125. doi:10.1016/j.biocon.2012.01.042

de Baan, L., Curran, M., Rondinini, C., Visconti, P., Hellweg, S., Koellner, T., 2015. Highresolution assessment of land use impacts on biodiversity in life cycle assessment using species habitat suitability models. Environ. Sci. Technol. 49, 2237-2244. doi:10.1021/es504380t

Di Bitetti, M.S., Placci, G., Dietz, L.A., 2003. A biodiversity vision for the Upper Parana Atlantic Forest ecoregion: designing a biodiversity conservation landscape and setting priorities for conservation action. 
Author-produced version of the article published in Ecological Indicators, 2018, N89, p.543-551.

The original publication is available at https://www.sciencedirect.com

Doi: 10.1016/j.ecolind.2018.01.068

Fischer, J., Lindenmayer, D.B., 2007. Landscape modification and habitat fragmentation: a synthesis. Glob. Ecol. Biogeogr. 16, 265-280. doi:10.1111/j.1466-8238.2006.00287.x

Flather, C.H., Bevers, M., 2002. Patchy reaction-diffusion and population abundance: the relative importance of habitat amount and arrangement. Am. Nat. 159, 40-56.

Forman, R.T.T., Alexander, L.E., 1998. Roads and Their Major Ecological Effects. Annu. Rev. Ecol. Syst. 29, 207-231. doi:10.1146/annurev.ecolsys.29.1.207

Gebauer, K., Dickinson, K.J.M., Whigham, P.A., Seddon, P.J., 2013. Matrix Matters : Differences of Grand Skink Metapopulation Parameters in Native Tussock Grasslands and Exotic Pasture Grasslands. PLoS One 8, 1-12. doi:10.1371/journal.pone.0076076

GEO BON, 2015. Global Biodiversity Change Indicators - Version 1.2.

Grilli, J., Barabás, G., Allesina, S., 2015. Metapopulation Persistence in Random Fragmented Landscapes. PLoS Comput. Biol. 11, 1-13. doi:10.1371/journal.pcbi.1004251

Haddad, N.M., Brudvig, L.A., Clobert, J., Davies, K.F., Gonzalez, A., Holt, R.D., Lovejoy, T.E., Sexton, J.O., Austin, M.P., Collins, C.D., Cook, W.M., Damschen, E.I., Ewers, R.M., Foster, B.L., Jenkins, C.N., King, A.J., Laurance, W.F., Levey, D.J., Margules, C.R., Melbourne, B.A., Nicholls, A.O., Orrock, J.L., Song, D., Townshend, J.R., 2015. Habitat fragmentation and its lasting impact on Earth's ecosystems. Sci. Adv. 1, 1-10.

Hanski, I., 2015. Habitat fragmentation and species richness. J. Biogeogr. 42, 989-993. doi:10.1111/jbi.12478

Hanski, I., 1998. Metapopulation dynamics. Nature 396, 41-49. 
Author-produced version of the article published in Ecological Indicators, 2018, N ${ }^{\circ} 89$, p.543-551.

The original publication is available at https://www.sciencedirect.com

Doi: 10.1016/j.ecolind.2018.01.068

608

609

Hanski, I., Ovaskainen, O., 2000. The metapopulation capacity of a fragmented landscape. Nature 404, 755-758. doi:10.1038/35008063

Hanski, I., Zurita, G.A., Bellocq, M.I., Rybicki, J., 2013. Species-fragmented area relationship, in: Proceedings of the National Academy of Sciences of the United States of America. pp. 12715-20. doi:10.1073/pnas.1311491110

Hellweg, S., Mila i Canals, L., 2014. Emerging approaches, challenges and opportunities in life cycle assessment. Science (80-. ). 344. doi:10.1126/science.1248361

Hietala-Koivu, R., Järvenpää, T., Helenius, J., 2004. Value of semi-natural areas as biodiversity indicators in agricultural landscapes. Agric. Ecosyst. Environ. 101, 9-19. doi:10.1016/S0167-8809(03)00273-1

Jaeger, J.A.G., 2000. Landscape division, splitting index, and effective mesh size: new measures of landscape fragmentation. Landsc. Ecol. 15, 115-130.

Kharouba, H.M., Mccune, J.L., Thuiller, W., Huntley, B., 2012. Do ecological differences between taxonomic groups influence the relationship between species' distributions and climate? A global meta-analysis using species distribution models. Ecography (Cop.). 35, 001-008. doi:10.1111/j.1600-0587.2012.07683.x

Kindlmann, P., Burel, F., 2008. Connectivity measures : a review. Landsc. Ecol. 23, 879-890. doi:10.1007/s10980-008-9245-4

Kupfer, J.A., 2012. Landscape ecology and biogeography: Rethinking landscape metrics in a post-FRAGSTATS landscape. Prog. Phys. Geogr. $2012 \quad 36$. doi:10.1177/0309133312439594 
Author-produced version of the article published in Ecological Indicators, 2018, N ${ }^{\circ} 89$, p.543-551.

The original publication is available at https://www.sciencedirect.com

Doi: 10.1016/j.ecolind.2018.01.068

Langford, W.T., Gergel, S.E., Dietterich, T.G., Cohen, W., 2006. Map Misclassification Can Cause Large Errors in Landscape Pattern Indices : Examples from Habitat Fragmentation. Ecosystems 9, 474-488. doi:10.1007/S10021-005-0119-1

Lenzen, M., Moran, D., Kanemoto, K., Lobefaro, L., Geschke, A., 2012. International trade drives biodiversity threats in developing nations. Nature 486, 109-112. doi:10.1038/nature11145

Loro, M., Ortega, E., Arce, R.M., Geneletti, D., 2015. Ecological connectivity analysis to reduce the barrier effect of roads. An innovative graph-theory approach to define wildlife corridors with multiple paths and without bottlenecks. Landsc. Urban Plan. 139, 149-162. doi:10.1016/j.landurbplan.2015.03.006

McGarigal, K., 1994. FRAGSTATS: spatial pattern analysis program for quantifying landscape structure.

Moran, D., Kanemoto, K., 2017. Identifying species threat hotspots from global supply chains. Nat. Ecol. Evol. 1, 1-5. doi:10.1038/s41559-016-0023

Myers, N., Mittermeier, R.A., Mittermeier, C.G., da Fonseca, G.A.B., Kent, J., 2000. Biodiversity hotspots for conservation priorities. Nature 403, 853-858.

Olson, D.M., Dinerstein, E., Wikramanayake, E.D., Burgess, N.D., Powell, G.V.N., Underwood, E.C., D’Amico, J.A., Itoua, I., Strand, H.E., Morrison, J.C., Loucks, C.J., Allnutt, T.F., Ricketts, T.H., Kura, Y., Lamoreux, J.F., Wettengel, W.W., Hedao, P., Kassem, K.R., 2001. Terrestrial Ecoregions of the World : A New Map of Life on Earth. Bioscience 51, 933-938.

Olsoy, P.J., Zeller, K.A., Hicke, J.A., Quigley, H.B., Rabinowitz, A.R., Thornton, D.H., 2016. 
Author-produced version of the article published in Ecological Indicators, 2018, N ${ }^{\circ} 89$, p.543-551.

The original publication is available at https://www.sciencedirect.com

Doi: 10.1016/j.ecolind.2018.01.068

Quantifying the effects of deforestation and fragmentation on a range-wide conservation plan for jaguars. Biol. Conserv. J. 203, 8-16.

Ortega, E., 2010. Indicator assessment for habitat fragmentation, in: COST 356 Final Conference.

Ovaskainen, O., Hanski, I., 2001. Spatially Structured Metapopulation Models: Global and Local Assessment of Metapopulation. Theor. Popul. Biol. 60, 281-302. doi:10.1006/tpbi.2001.1548

Pardini, R., De Arruda Bueno, A., Gardner, T.A., Inacio Prado, P., Metzger, J.P., 2010. Beyond the Fragmentation Threshold Hypothesis: Regime Shifts in Biodiversity Across Fragmented Landscapes. PLoS One 5. doi:10.1371/journal.pone.0013666

Potapov, P., Hansen, M.C., Laestadius, L., Turubanova, S., Yaroshenko, A., Thies, C., Smith, W., Zhuravleva, I., Komarova, A., Minnemeyer, S., Esipova, E., 2017. The last frontiers of wilderness : Tracking loss of intact forest landscapes from 2000 to 2013. Sci. Adv. 3, 1-13.

QGIS Development Team, 2017, 2017. QGIS Geographic Information System. Open Source Geospatial Foundation Project. [WWW Document]. URL http://www.qgis.org/

Radford, J.Q., Bennett, A.F., Cheers, G.J., 2005. Landscape-level thresholds of habitat cover for woodland-dependent birds. Biol. Conserv. 124, 317-337. doi:10.1016/j.biocon.2005.01.039

Ricketts, T.H., 2001. The Matrix Matters: Effective Isolation in Fragmented Landscapes. Am. Nat. 158, 87-99.

Riitters, K., Wickham, J., O’Neill, R., Jones, B., Smith, E., 2000. Global-Scale Patterns of Forest Fragmentation. Conserv. Ecol. 4. 
Author-produced version of the article published in Ecological Indicators, 2018, N ${ }^{\circ} 89$, p.543-551.

The original publication is available at https://www.sciencedirect.com

Doi: 10.1016/j.ecolind.2018.01.068

Russell A. Mittermeier, Patricio Robles Gil, Michael Hoffman, John Pilgrim, Thomas Brooks, Cristina Goettsch Mittermeier, John Lamoreux, Gustavo A. B. da Fonseca, 2004. Hotspots Revisited: Earth's Biologically Richest and Most Endangered Terrestrial Ecoregions, Revised. ed. Conservation International.

Rutledge, D., 2003. Landscape indices as measures of the effects of fragmentation: can pattern reflect process? DOC Science Internal Series.

Rybicki, J., Hanski, I., 2013. Species-area relationships and extinctions caused by habitat loss and fragmentation. Ecol. Lett. 16, 27-38. doi:10.1111/ele.12065

Saura, S., 2004. Effects of remote sensor spatial resolution and data aggregation on selected fragmentation indices. Landsc. Ecol. 19, 197-209.

Saura, S., Torne, J., 2009. Environmental Modelling \& Software Conefor Sensinode 2.2: A software package for quantifying the importance of habitat patches for landscape connectivity. Environ. Model. Softw. 24, 135-139. doi:10.1016/j.envsoft.2008.05.005

Schneider, M.F., 2001. Habitat loss, fragmentation and predator impact : spatial implications for prey conservation. J. Appl. Ecol. 38, 720-735.

Schnell, J.K., Harris, G.M., Pimm, S.L., Russell, G.J., 2013a. Quantitative Analysis of Forest Fragmentation in the Atlantic Forest Reveals More Threatened Bird Species than the Current Red List. PLoS One 8, 36-37. doi:10.1371/journal.pone.0065357

Schnell, J.K., Harris, G.M., Pimm, S.L., Russell, G.J., 2013b. Estimating Extinction Risk with Metapopulation Models of Large-Scale Fragmentation. Conserv. Biol. 27, 520-530. doi:10.1111/cobi.12047 
Author-produced version of the article published in Ecological Indicators, 2018, N ${ }^{\circ} 89$, p.543-551.

The original publication is available at https://www.sciencedirect.com

Doi: 10.1016/j.ecolind.2018.01.068

Secretariat of the Convention on Biological Diversity, 2014. Global Biodiversity Outlook 4. doi:10.2143/KAR.25.0.504988

Shima, J.S., Noonburg, E.G., Phillips, N.E., 2010. Life history and matrix heterogeneity interact to shape metapopulation connectivity in spatially structured environments. Ecology 91, $1215-1224$.

Sloan, S., Jenkins, C.N., Joppa, L.N., Gaveau, D.L.A., Laurance, W.F., 2014. Remaining natural vegetation in the global biodiversity hotspots. Biol. Conserv. 177, 12-24. doi:10.1016/j.biocon.2014.05.027

Sutherland, G.D., Harestad, A.S., Price, K., Lertzman, K.P., 2000. Scaling of Natal Dispersal Distances in Terrestrial Birds and Mammals. Conserv. Ecol. 4.

Taylor, P.D., Fahrig, L., Henein, K., Merriam, G., 1993. Connectivity is a vital element of landscape structure. Oikos 68, 571-573.

Travis, J.M.J., French, D.R., 2000. Dispersal functions and spatial models: expanding our dispersal toolbox. Ecol. Lett. 3, 163-165.

Vandermeer, J., Carvajal, R., 2001. Metapopulation Dynamics and the Quality of the Matrix. Am. Nat. 158, 211-220.

Verheyen, K., Vellend, M., Calster, H. Van, Peterken, G., Hermy, M., 2004. Metapopulation Dynamics in Changing Landscapes: A New Spatially Realistic Model for Forest Plants. Ecology 85, 3302-3312.

Wang, X., Blanchet, F.G., Koper, N., 2014. Measuring habitat fragmentation: An evaluation of landscape pattern metrics. Methods Ecoloy Evol. 5, 634-646. doi:10.1111/2041- 
714 Whitmore, T.C., Sayer, J.A., 1992. Tropical Deforestation and Species Extinction. Chapman \& 715 Hall, for the IUCN.

716 Wilcove, D.S., McLellan, C.H., Dobson, A.P., 1986. Habitat fragmentation in the temperate zone, in: Soulé, M.E. (Ed.), Conservation Biology - The Science of Scarcity and Diversity. Sinauer Associates, Inc., pp. 237-256.

719 WWF, 2016a. Living Planet Report 2016 - Risk and resilience in a new era.

720 WWF, 2016b. WWF - Our Global Goals: Forests [WWW Document]. URL 12.16.16). 